\title{
Exploring the Core Attributes of Digitalization Causing High Impact on Learning Trends Of Students Using LIFAM
}

\author{
Nivetha Martin $^{1}$ *, P.Pandiammal ${ }^{2}$ \\ ${ }^{1}$ Department of Mathematics, Arul Anandar College (Autonomous), Karumathur \\ ${ }^{2}$ Department of Mathematics, GTN Arts College (Autonomous), Dindigul \\ *Corresponding author E-mail :nivetha.martin710@gmail.com
}

\begin{abstract}
In the existing educational scenario, the mechanisms of teaching and learning that are conventional have to be enriched unanimously to promote the development of the student community in all dimensions. The present government rings the bell of Digital India, which targets in making the service sectors to be digitally empowered. But in recent days, digitalization has stepped into almost all the fields and education is not an exception to it. The traditional blackboard teaching method was replaced by ICT techniques, but the learning strategies remained customary. To bring a change in the learning mode, the student community has to be provided a platform to learn at their own pace, which can be achieved by imparting the digital way of learning. Incorporation of Digitalization into teaching cum learning domains will pave way for Glean knowledge. Though there are many confrontations in implementation, the degree of the positive effects is high. This paper primarily aims in determining the effects of core factors of digitalization causing major effects on student's learning mode using a novel approach of Linguistic Induced Fuzzy Associative Memories (LIFAM).
\end{abstract}

Keyword: Associative memories;Digitalization;Fuzzy;learning trends;Linguistic variable

\section{Introduction}

Digital mode of education has opening gates in the present Indian educational system and the developments towards it are taking place colossally[1,2]. The introduction of ICT has laid a new pattern for teaching but the learning mode remained static [3]. The venture of digitalization has provided wide space for the learners to relax from the conventional methods of learning. In the scenario of digitalization the strict adherence to the classes, submission of written assignments, appearing for examinations, appraisals will be switched to digital mode; learning process will take place at one's own hustle; new ways of learning will come into practice. Thus the absorption of digitalization will result in paradigm shift from conventional learning practices to contemporary trends. [4] To examine the effects of digitalization on learning trends of student, the concept of Linguistic Induced Fuzzy Associative Memories (LIFAM) is used in this paper, which is the extended form of Induced Fuzzy Associative Memories (IFAM). The concept of Fuzzy Associative Memories was introduced by the researchers to make decisions and interrupt on the impacts of distinct associated factors. The pioneers of the earlier developed models are Kosko [5],Balasangu [6] and so on and it was extended in recent years by many researchers $[7,8,9]$ in this field. The proposed method of LIFAM gets the raw data from the expert's opinion in terms of linguistic variable which reflects the degree of impacts.[10,11] The paper is organized as follows: section 2 consists of the basic definitions, section 3 encompasses the steps involved in the proposed method, section 4 comprises of the adaptation of the proposed method to the problem considered, section 5 presents the results and discussion and the last section concludes the paper.

\section{Preliminaries}

\section{Fuzzy Set}

A nonempty set A and the universal set X, with a membership function defined as $\mathrm{A}: \mathrm{X} \rightarrow[0,1]$ is called as fuzzy set.

Fuzzy Associative Memories (FAM)

FAM is a mapping of close inputs to close outputs and it is represented as $\mathrm{S}: \mathrm{I}^{\mathrm{n}} \rightarrow \mathrm{I}^{\mathrm{P}}$, where $\mathrm{I}^{\mathrm{n}} \& \mathrm{I}^{\mathrm{P}}$ are the collection of fuzzy subsets of the domain and range space respectively.

Hexagonal fuzzy number

A depiction of a fuzzy number of the $\mathrm{H}=(a 1, a 2, a 3, a 4, a 5, a 6)$ such that all ai's are real numbers and $a 1 \leq a 2 \leq a 3 \leq a 4 \leq a 5 \leq a 6$ is called as Hexagonal Fuzzy number with the membership function as

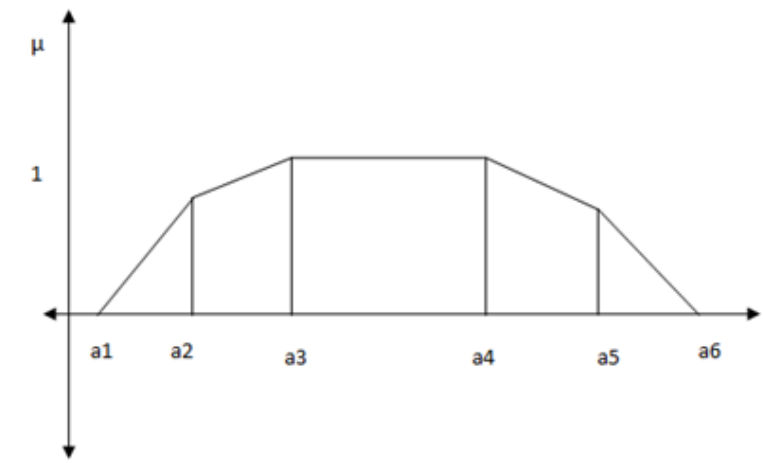

Fig.1.Membership Function of Hexagonal Fuzzy Number 


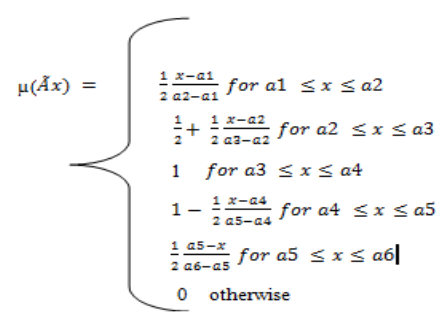

\section{Relational Matrix of FCM}

The matrix obtained out of the pictorial representation of the association of the concepts.

\section{Linguistic Variable}

A variable which takes linguistic values rather numeric.

\section{Proposed Method of LIFAM}

The steps involved are as follows:

1. The attributes related to the problem of decision making are taken as the nodes of domain and range space.

2. The connection/relational matrix with linguistic values is obtained from the expert's opinion.

3. The linguistic connection matrix is converted to Hexagonal connection matrix by quantifying the linguistic variables using hexagonal fuzzy numbers.

4. The average Hexagonal relational matrix $\mathrm{R}$ is obtained after defuzzification.

5. The vector $\mathrm{C} 1$ is kept in $\mathrm{ON}$ stage and it is passed to $\mathrm{R}$ and the resultant is thresholded by assigning 1 to first two higher values and 0 for others, which is once again passed into $R^{T}$. The resultant is again thresholded.

6. The same procedure is repeated for the thresholded vector by considering the occurrence of 1's individually. The resultant vector with maximum number of 1 's is taken as $\mathrm{C} 2$.

7. The steps are applied continually until the limit point is attained. (i.e. $\mathrm{Ci}=\mathrm{Cj}$ )

\section{Adaptation of LIFAM to the Problem}

The following attributes are associated with the effects of Digitalization and they are considered as the nodes of the domain space.

D1 Learning takes place at one's own pace

D2 Lack of time constraint

D3 Enhancement of learning performance

D4 Immense increase in the comprehension of concepts

D5 Students are kept engaged

D6 High choice in Specification

D7 Bridge the gap between theory and its application

The below attributes are related with the learning trends of students and they are taken as the nodes of range space.

L1 Increase of interest in learning

L2 Learning becomes simple and scientific

L3 Students are relieved from scheduled learning pattern

L4 Acquisition of knowledge from various sources

L5 Visualization of theoretical concepts

L6 Student's creativity is improved

The linguistic opinion of proficient persons presently integrated with the field of education system is presented in the form of relational matrix $\mathrm{R}$

$\begin{array}{lllllll} & \text { L1 } & \text { L2 } & \text { L3 } & \text { L4 } & \text { L5 } & \text { L6 } \\ \text { D1 } & \text { H } & \text { H } & \text { VH } & \text { H } & \text { H } & \text { M } \\ \text { D2 } & \text { H } & \text { VH } & \text { H } & \text { M } & \text { L } & \text { L } \\ \text { D3 } & \text { VL } & \text { L } & \text { L } & \text { M } & \text { M } & \text { H } \\ \text { D4 } & \text { M } & \text { H } & \text { M } & \text { M } & \text { H } & \text { H } \\ \text { D5 } & \text { M } & \text { L } & \text { M } & \text { L } & \text { L } & \text { M } \\ \text { D6 } & \text { H } & \text { H } & \text { H } & \text { H } & \text { H } & \text { H } \\ \text { D7 } & \text { VH } & \text { H } & \text { H } & \text { H } & \text { VH } & \text { VH }\end{array}$

The Hexagonal quantification of linguistic terminologies is as follows

Table.1.Hexagonal quantification of linguistic variablesThe modified linguistic relational matrix is given below

\begin{tabular}{|l|l|}
\hline Very Low & $(0,0.05,0.1,0.15,0.2,0.25)$ \\
\hline Low & $(0.15,0.2,0.25,0.3,0.35,0.4)$ \\
\hline Medium & $(0.3,0.35,0.4,0.45,0.5,0.55)$ \\
\hline High & $(0.45,0.5,0.55,0.6,0.65,0.7)$ \\
\hline Very High & $(0.65,0.7,0.75,0.8,0.9,1)$ \\
\hline
\end{tabular}

$\begin{array}{lllllll} & \text { L1 } & \text { L2 } & \text { L3 } & \text { L4 } & \text { L5 } & \text { L6 } \\ \text { D } & (0.45,0.5,0 & (0.45,0.5,0 & (0.65,0.7,0 & (0.45,0.5,0 & (0.45,0.5,0 & (0.3,0.35,0 \\ 1 & .55,0.6,0.6 & .55,0.6,0.6 & .75,0.8,0.9, & .55,0.6,0.6 & .55,0.6,0.6 & .4,0.45,0.5, \\ & 5,0.7) & 5,0.7) & 1) & 5,0.7) & 5,0.7) & 0.55) \\ \text { D } & (0.45,0.5,0 & (0.65,0.7,0 & (0.45,0.5,0 & (0.3,0.35,0 & (0.15,0.2,0 & (0.15,0.2,0 \\ 2 & .55,0.6,0.6 & .75,0.8,0.9, & .55,0.6,0.6 & .4,0.45,0.5, & .25,0.3,0.3 & .25,0.3,0.3 \\ & 5,0.7) & 1) & 5,0.7) & 0.55) & 5,0.4) & 5,0.4) \\ \mathrm{D} & (0,0.05,0.1,0 . & (0.15,0.2,0.2 & (0.15,0.2,0.2 & (0.3,0.35,0 & (0.3,0.35,0 & (0.45,0.5,0 \\ 3 & 15,0.2,0.25) & 5,0.3,0.35,0 . & 5,0.3,0.35,0 . & .4,0.45,0.5, & .4,0.45,0.5, & .55,0.6,0.6 \\ & & 4) & 4) & 0.55) & 0.55) & 5,0.7) \\ \mathrm{D} & (0.3,0.35,0 & (0.45,0.5,0 & (0.3,0.35,0 & (0.3,0.35,0 & (0.45,0.5,0 & (0.45,0.5,0 \\ 4 & .4,0.45,0.5, & .55,0.6,0.6 & .4,0.45,0.5, & .4,0.45,0.5, & .55,0.6,0.6 & .55,0.6,0.6 \\ & 0.55) & 5,0.7) & 0.55) & 0.55) & 5,0.7) & 5,0.7) \\ \mathrm{D} & (0.3,0.35,0 & (0.15,0.2,0.2 & (0.3,0.35,0 & (0.15,0.2,0.2 & (0.15,0.2,0.2 & (0.3,0.35,0 \\ \mathrm{S} & .4,0.45,0.5, & 5,0.3,0.35,0 . & .4,0.45,0.5, & 5,0.3,0.35,0 . & 5,0.3,0.35,0 . & .4,0.45,0.5, \\ & 0.55) & 4) & 0.55) & 4) & 4) & 0.55) \\ \mathrm{D} & (0.45,0.5,0 & (0.45,0.5,0 & (0.45,0.5,0 & (0.45,0.5,0 & (0.45,0.5,0 & (0.45,0.5,0 \\ 6 & .55,0.6,0.6 & .55,0.6,0.6 & .55,0.6,0.6 & .55,0.6,0.6 & .55,0.6,0.6 & .55,0.6,0.6 \\ & 5,0.7) & 5,0.7) & 5,0.7) & 5,0.7) & 5,0.7) & 5,0.7) \\ \mathrm{D} & (0.65,0.7,0 & (0.45,0.5,0 & (0.45,0.5,0 & (0.45,0.5,0 & (0.65,0.7,0 & (0.65,0.7,0 \\ 7 & .75,0.8,0.9, & .55,0.6,0.6 & .55,0.6,0.6 & .55,0.6,0.6 & .75,0.8,0.9, & .75,0.8,0.9 \\ & 1) & 5,0.7) & 5,0.7) & 5,0.7) & 1) & 1)\end{array}$

The Average Hexagonal matrix is

$\begin{array}{lllllll} & \text { L1 } & \text { L2 } & \text { L3 } & \text { L4 } & \text { L5 } & \text { L6 } \\ \text { D1 } & 1.2 & 1.2 & 1.6 & 1.2 & 1.2 & 0.9 \\ \text { D2 } & 1.2 & 1.6 & 1.2 & 0.9 & 0.6 & 0.6 \\ \text { D3 } & 0.3 & 0.6 & 0.6 & 0.9 & 0.9 & 1.2 \\ \text { D4 } & 0.9 & 1.2 & 0.9 & 0.9 & 1.2 & 1.2 \\ \text { D5 } & 0.9 & 0.6 & 0.9 & 0.6 & 0.6 & 0.9 \\ \text { D6 } & 1.2 & 1.2 & 1.2 & 1.2 & 1.2 & 1.2 \\ \text { D7 } & 1.6 & 1.2 & 1.2 & 1.2 & 1.6 & 1.6\end{array}$

Let $\mathrm{C} 1=(1000000)$

$\mathrm{C} 1 * \mathrm{R}=(1.21 .21 .61 .21 .20 .9) \hookrightarrow(111110)=\mathrm{C} 1$

$\mathrm{C} 1 * \mathrm{R}^{\mathrm{T}}=\left(\begin{array}{ll}6.45 .53 .35 .13 .666 .8 & 4\end{array}(1000001)=\mathrm{C} 1\right.$

$\mathrm{C} 1^{1}=(1000000)$

$\mathrm{C}^{2}=(0000001)$

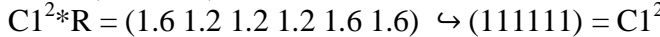

$\mathrm{C}^{2} * \mathrm{R}^{\mathrm{T}}=(7.36 .14 .56 .34 .57 .28 .4) \hookrightarrow(1000001)$

Let $\mathrm{C} 2=(1000001)$

$\mathrm{C} 2 * \mathrm{R}=\left(\begin{array}{lll}2.8 & 2.4 & 2.82 .42 .82 .5\end{array}\right) \hookrightarrow(101011)=\mathrm{C} 2$

$\mathrm{C} 2 * \mathrm{R}^{\mathrm{T}}=(4.93 .634 .23 .34 .86) \hookrightarrow(1000010)$

$\mathrm{C} 2^{1}=(1000000)$

$\mathrm{C}^{2}=(0000010)$

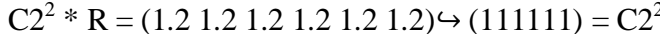

$\mathrm{C} 2^{2} * \mathrm{R}^{\mathrm{T}}=((7.36 .14 .56 .34 .57 .28 .4) \hookrightarrow(1000001)=\mathrm{C} 3$ 
$\mathrm{C} 3^{1}=(1000000)$

$\mathrm{C}^{2}=(0000001)$

$\mathrm{C}^{2} * \mathrm{R}=(1.61 .21 .21 .21 .61 .6) \hookrightarrow(111111)=\mathrm{C} 3^{2}$

$\mathrm{C}^{2} * \mathrm{R}^{\mathrm{T}}=(7.36 .14 .56 .34 .57 .28 .4) \hookrightarrow(1000001)=\mathrm{C} 4$

$\mathrm{C} 2=\mathrm{C} 4$

The limit point is $\{(111111),(1000001)\}$

Let $\mathrm{C} 1=(0100000)$

$\mathrm{C} 1 * \mathrm{R}=(1.21 .61 .20 .90 .60 .6) \hookrightarrow(111000)=\mathrm{C} 1$

$\mathrm{C} 1 * \mathrm{R}^{\mathrm{T}}=\left(\begin{array}{ll}4 & 4 \\ 1.5 & 32.43 .64\end{array}\right) \hookrightarrow(1100011)=\mathrm{C} 1$

$\mathrm{C} 1^{1}=(1000000)$

$\mathrm{Cl}^{2}=(0100000)$

$\mathrm{Cl}^{3}=(0000010)$

$\mathrm{Cl}^{4}=(0000001)$

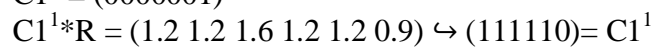

$\mathrm{C} 1^{1} * \mathrm{R}^{\mathrm{T}}=(6.45 .53 .35 .13 .666 .8) \hookrightarrow(1000001)=\mathrm{C} 1^{1}$

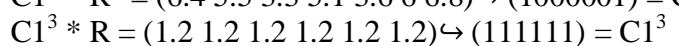

$\mathrm{C}^{3} * \mathrm{R}^{\mathrm{T}}=\left((7.36 .14 .56 .34 .57 .28 .4) \hookrightarrow(1000001)=\mathrm{Cl}^{3}\right.$

$\mathrm{C} 1^{4} * \mathrm{R}=(1.61 .21 .21 .21 .61 .6) \hookrightarrow(111111)=\mathrm{Cl}^{4}$

$\mathrm{C}^{4} * \mathrm{R}^{\mathrm{T}}=(7.36 .14 .56 .34 .57 .28 .4) \hookrightarrow(1000001)=\mathrm{C} 1^{4}$

The limit point is $\{(111111),(1000001)\}$

Let $\mathrm{C} 1=(0010000)$

$\mathrm{C} 1 * \mathrm{R}=\left(\begin{array}{l}0.3 \\ 0.6\end{array} 0.60 .90 .91 .2\right) \hookrightarrow(000111)=\mathrm{C} 1$

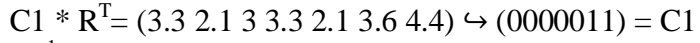

$\mathrm{C} 1^{1}=(0000010)$

$\mathrm{C}^{2}=(0000001)$

$\mathrm{C} 1^{1} * \mathrm{R}=\left(\begin{array}{lll}1.2 & 1.2 & 1.2 \\ 1.2 & 1.2 & 1.2\end{array}\right) \hookrightarrow(111111)=\mathrm{C} 1^{1}$

$\mathrm{C} 1^{1} * \mathrm{R}^{\mathrm{T}}=(7.36 .14 .56 .34 .57 .28 .4) \hookrightarrow(1000001)=\mathrm{C} 1^{1}$

$\mathrm{C}^{2} * \mathrm{R}=(1.61 .21 .21 .21 .61 .6) \hookrightarrow(111111)=\mathrm{C}^{2}$

$\mathrm{C} 1^{2} * \mathrm{R}^{\mathrm{T}}=(7.36 .14 .56 .34 .57 .28 .4) \hookrightarrow(1000001)=\mathrm{C}^{2}$

The limit point is $\{(111111),(1000001)\}$

Let $\mathrm{C} 1=(0001000)$

$\mathrm{C} 1 * \mathrm{R}=(0.91 .20 .90 .91 .21 .2) \hookrightarrow(111111)=\mathrm{C} 1$

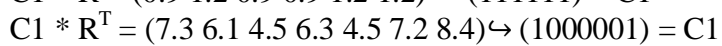

$\mathrm{C} 1^{1}=(1000000)$

$\mathrm{C}^{2}=(0000001)$

$\mathrm{C} 1^{2} * \mathrm{R}=(1.61 .21 .21 .21 .61 .6) \hookrightarrow(111111)=\mathrm{C}^{2}$

$\mathrm{C}^{2} * \mathrm{R}^{\mathrm{T}}=(7.36 .14 .56 .34 .57 .28 .4) \hookrightarrow(1000001)$

Let $\mathrm{C} 2=(1000001)$

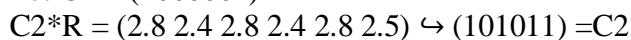

$\mathrm{C} 2 * \mathrm{R}^{\mathrm{T}}=(4.93 .634 .23 .34 .86) \hookrightarrow(1000010)$

$\mathrm{C} 2{ }^{1}=(1000000)$

$\mathrm{C}^{2}=(0000010)$

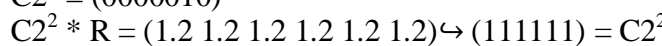

$\mathrm{C} 2^{2} * \mathrm{R}^{\mathrm{T}}=((7.36 .14 .56 .34 .57 .28 .4) \hookrightarrow(1000001)=\mathrm{C} 3$

$\mathrm{C} 3^{1}=(1000000)$

$\mathrm{C} 3^{2}=(0000001)$

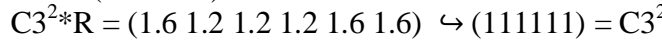

$\mathrm{C}^{2} * \mathrm{R}^{\mathrm{T}}=(7.36 .14 .56 .34 .57 .28 .4) \hookrightarrow(1000001)=\mathrm{C} 4$

$\mathrm{C} 2=\mathrm{C} 4$

The limit point is $\{(111111),(1000001)\}$

Let $\mathrm{C} 1=(0000100)$

$\mathrm{C} 1 * \mathrm{R}=(0.90 .60 .90 .60 .60 .9 \hookrightarrow(111111)=\mathrm{C} 1$

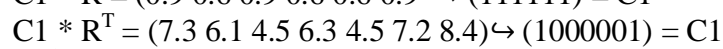

$\mathrm{C} 1^{1}=(1000000)$

$\mathrm{C}^{2}=(0000001)$

$\mathrm{C} 1^{2} * \mathrm{R}=(1.61 .21 .21 .21 .61 .6) \hookrightarrow(111111)=\mathrm{Cl}^{2}$

$\mathrm{C} 1^{2} * \mathrm{R}^{\mathrm{T}}=(7.36 .14 .56 .34 .57 .28 .4) \hookrightarrow(1000001)$

Let $\mathrm{C} 2=(1000001)$

$\mathrm{C} 2 * \mathrm{R}=\left(\begin{array}{llll}2.8 & 2.4 & 2.8 & 2.4 \\ 2.8 & 2.5\end{array}\right) \hookrightarrow(101011)=\mathrm{C} 2$

$\mathrm{C} 2 * \mathrm{R}^{\mathrm{T}}=(4.93 .634 .23 .34 .86) \hookrightarrow(1000010)$

$\mathrm{C} 2^{1}=(1000000)$

$\mathrm{C} 2^{2}=(0000010)$

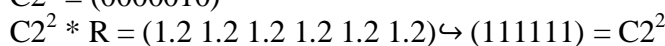

$\mathrm{C} 2^{2} * \mathrm{R}^{\mathrm{T}}=((7.36 .14 .56 .34 .57 .28 .4) \hookrightarrow(1000001)=\mathrm{C} 3$

$\mathrm{C} 3^{1}=(1000000)$

$\mathrm{C}^{2}=(0000001)$

$\mathrm{C}^{2} * \mathrm{R}=(1.61 .21 .21 .21 .61 .6) \hookrightarrow(111111)=\mathrm{C} 3^{2}$

$\mathrm{C}^{2} * \mathrm{R}^{\mathrm{T}}=(7.36 .14 .56 .34 .57 .28 .4) \hookrightarrow(1000001)=\mathrm{C} 4$

$\mathrm{C} 2=\mathrm{C} 4$

The limit point is $\{(111111),(1000001)\}$
Let $\mathrm{C} 1=(0000010)$

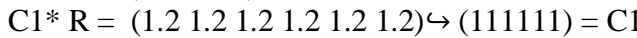

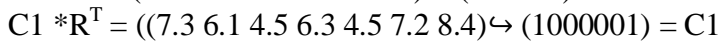

From the previous steps

The limit point is $\{(111111),(1000001)\}$

Let $\mathrm{C} 1=(0000001)$

From the previous steps

The limit point is $\{(111111),(1000001)\}$

Table.2. Input vector \& Limit Point

\begin{tabular}{|l|l|}
\hline Input Vector & Limit Point \\
\hline$(1000000)$ & $(11111),(1000001)$ \\
\hline$(0100000)$ & $(111111),(1000001)$ \\
\hline$(0010000)$ & $(11111),(1000001)$ \\
\hline$(0001000)$ & $(11111),(1000001)$ \\
\hline$(0000100)$ & $(11111),(1000001)$ \\
\hline$(0000010)$ & $(11111),(1000001)$ \\
\hline
\end{tabular}

\section{Results and Discussion}

From the below table, the limit point (111111),(1000001) clearly explicates that the factor D1 \& D7 are the core factors of digitalization, which influence the learning trends of the students to high extent. The factors Learning takes place at one's own pace and Bridge the gap between theory and its application are two hub factors which have high degree of impacts on the factors related to student's learning trends considered in the range space. The digitalized education will duly assist the student community to learn at their own space and it will also enable them to comprehend the theoretical aspects and its real time applications.

\section{Conclusion}

This research work puts forth a new method of LIFAM which considers the realistic opinion of the experts into account for further analysis. This paper discusses about the attributes of effects of digitalization on the learning trends of the students and the association between the factors of domain and range space. The quantification of linguistic variable can be made using the other higher order fuzzy numbers which pave way for extending this work.

\section{References}

[1] Li, Q., Ma, X. A meta-analysis of the effects of computer technology on school students' mathematics learning. Educational Psychology Review, 22.3,2010,215-243.

[2] Liao, Y. ,Effects of computer-assisted instruction on students' achievement in Taiwan: A meta-analysis Computers \& Education 48,2005,216-233.

[3] Torgerson C.J.,Elbourne D.,A Systematic Review and MetaAnalysis of the Effectiveness of Information and Communication Technology (ICT) on the Teaching of Spelling. Journal of Research in Reading 25,2002,129-43.

[4] Camilleri, Digital Learning Resources and Ubiquitous Technologies in Education,Tech Know Learn, 5,6,2016,65-82. .

[5] Kosko.B, Fuzzy cognitive maps, Int, J. Man-Machine studies, 24, 1986,65-75.

[6] Balasangu. K IFAM model approach onthe impact of pesticides on agricultural labourers, Indian Journal of Science and Technology, 4,2,2011, 262-268.

[7] Lilly Merline, Aleeswari.D,Nivetha Martin ,An Analysis of Traditional Catastrophe in Tamil Nadu Using NEDIFVAM, Middle East Journal of Scientific Research,25,2,2017,358-361

[8] Nivetha Martin., P.Pandiammal ,Reasons for Adolescent's Social Network addiction and its impact on Academics -An Analysis using Induced Linked Fuzzy Relational Mapping Using Hexagonal Fuzzy number, Elixir, Educational Technology, 20,1,2016,41914-41917.

[9] Nivetha Martin., C.Mabel Joshaline,An Analysis of the influential advantage of bio treatment over mechanical processing in conversion of $\mathrm{Cr}$ (VI) to Cr (III) in Leather Industry using Fuzzy Cogni- 
tive Maps, International Journal of Advanced Engineer-

ing,Management and Science, 2,7, 2016, 1037-1040.

[10] Pathinathan T., et al.,On Tensions and Causes for School Dropouts

- An Induced LinkedFuzzy Relational Mapping (ILFRM) Analysis, In Proc. Of the 9th Joint Conference on Information Sciences (JCIS), 2013, 1160-1163.

[11] Vasantha Kandasamy W.B., and P.Pramodh, Parent Children model using FCM to study dropout to Primary Education, Ultra Sciences, 13,3,2001,362-367. 